\title{
Formação em aleitamento materno e suas repercussões na prática clínica
}

\author{
Education in maternal breastfeeding and their repercussions in clinical practice \\ Formación en lactancia materna y sus repercusiones en la práctica clínica
}

\section{Dulce Garcia Galvão'}

'Escola Superior de Enfermagem. Coimbra, Portugal

\author{
Submissão: 17/01/2010Ａ ～Aprovação: 20/11/2010
}

\section{RESUMO}

O estudo objetivou identificar as orientações Que o enfermeiro disponibiliza às mães Quanto à amamentação e verificar Que habilidades de comunicação são utilizadas no aconselhamento em aleitamento materno. Tratou-se de estudo descritivo-exploratório sendo aplicado um Questionário o Qual foi preenchido por 45 enfermeiros estudantes de um curso de especialização em pediatria. A média de idade dos participantes foi 32,7 anos, sendo a maioria do sexo feminino. Verificou-se que após o aprendizado os participantes passaram a estar mais despertos para a postura corporal materna e anatomia da mama. Houve modificação dos informações disponibilizadas às mães para práticas mais adeQuadas relativas ao posicionamento e modo de mamar, mas foram poucas as habilidades comunicacionais utilizadas. Concluiu-se Que a formação sobre aconselhamento não foi suficiente, reQuerendo maior desenvolvimento.

Descritores: Aleitamento materno; Aconselhamento; Promoção da saúde; Enfermeiros.

\section{ABSTRACT}

The study aimed at understanding the aspects that the nurses makes available to mothers regarding to breastfeeding and to verify which communication skills are used in advice in breastfeeding. That was a descriptive-exploratory study with the use of an aplication form that was completed by 45 nurses from a post-graduate pediatrics course. The average age of the participants was 32,7 years-old, being the majority females. It was observed that after the training course the students become more aware of the maternal body posture and breast anatomy. Changes in the advices given to the mothers with the purpose of promoting better practices concerning to the positioning and way of nursing were also observed after the training, nevertheless, the communication skills used were few. It was concluded that the breastfeeding advice training course was not enough, requiring a greater development.

Descriptors: Breastfeeding; Advice; Health Promotion; Nurses.

\section{RESUMEN}

El estudio objetivó identificar las orientaciones que el enfermero torna disponible a las madres cuanto a la lactancia materna y verificar Que habilidades de comunicación son usadas el el asesoramineto em la lactancia materna. Tratose de um estudio descriptivo-exploratorio con la aplicación de un cuestionario lo caul hay sido completado por 45 enfermeros de un curso de post-grado en pediatria. La média de edad hay sido de 32,7 años, siendo la mayoria del sexo femenino. Señalando Que después de la enseñanza comenzaron a prestar más atención a la postura corporal materna y la anatomía del seno, hubo cambio en el consejos dados a las madres para mejores práticas relativas a la colocación y el método de alimentación, pero hubo pocas habilidades de comunicación utilizados y se concluyó Que la capacitación sobre consejo sobre lactancia materna no fue suficiente, requiere más horas de desarrollo.

Descriptores: Lactancia materna; Asesoramiento; Promoción de la salud; Enfermeros 


\section{INTRODUÇÃO}

A amamentação é uma das formas mais eficazes de contribuir para a melhoria do estado de saúde da criança, das mães, das famílias, do ambiente e da sociedade em geral, todavia o abandono precoce é uma realidade com Que nos deparamos com alguma frequência, pelo Que a sua proteção, promoção e suporte constitui uma prioridade de saúde pública. Vários são os fatores Que conduzem a tal situação destacando-se as práticas dos profissio-nais de saúde como uma das medidas mais influentes de aumentar a sua prevalência e duração(l).

A lactação é um processo fisiológico normal, uma consequência de dar à luz e em muitos países a única forma de assegurar a sobrevivência e o crescimento saudável de um recém-nascido (RN). Os problemas da lactação poderão surgir se o processo fisiológico é alterado por aplicação de regras e normas artificiais ou por não se conseguir colocar o bebé à mama de modo adequado. Para que o bebê mame corretamente há Que ensinar tanto a mãe como o bebê $\mathrm{o}$ Que constitui colocar-se à mama de uma forma eficaz ${ }^{(2)} \mathrm{e}$ uma das medidas recomendadas pelo Fundo das Nações Unidas para a Infância (UNICEF), Que visa identificar situações de dificuldade no início da amamentação, Que podem favorecer o desmame precoce, é a observação e avaliação de cada dupla mãe/bebê durante uma mamada por meio de protocolo específico ${ }^{(3)}$. Este protocolo permite avaliar a postura corporal da mãe e bebê, as respostas do bebê, o vínculo emocional, a anatomia das mamas e a sucção ${ }^{(1)}$. A observação da mamada possibilita uma atuação mais efetiva e direta da equipa de saúde permitindo identificar se a mãe precisa de ajuda e Que tipo de ajuda, favorecendo assim o estabelecimento da amamentação(I).

Outro fator Que afeta a iniciação e o estabelecimento normais do aleitamento é o modo como os profissionais de saúde abordam as mães Quando fazem aconselhamento em aleitamento materno ${ }^{(4)}$. Nesta abordagem há necessidade de se desenvolver um conjunto de competências comunicacionais ${ }^{(1)}$. O profissional de saúde ouve e tenta entender como a mãe se sente, procura ajudar a mãe a decidir o Que é melhor para si, a decidir o Que fazer, e a adQuirir auto-confiança. Procura-se ajudar a mãe a viver o processo de amamentação de modo saudável, tanto a nível biológico, como sensorial e psíQuico. É neste contexto Que Bueno e Teruya ${ }^{(5)}$ alertam para a diferença entre aconselhar e aconselhamento, afirmando Que o primeiro conceito consiste em dizer-se à pessoa o Que deve fazer e que aconselhamento é uma forma de atuação do profissional com a mãe onde ele a escuta, procura compreendê-la e, com os seus conhecimentos, oferece ajuda, de modo a dar oportunidade à mãe a planejar, tomar decisões e a fortalecer-se para lidar com pressões, aumentando a sua autoconfiança e auto-estima.

Tendo presente estas premissas, importantes para o sucesso da amamentação, e como responsável pela formação de futuros enfermeiros especialistas em enfermagem de saúde infantil e pediatria, surgiu a necessidade de se incluir no programa da unidade curricular vocacionada para o processo de crescimento e desenvolvimento da criança, do Curso de Pós Licenciatura de Especialização de Enfermagem de Saúde Infantil e Pediatria de uma Escola Superior de Enfermagem, os conteúdos programáticos "Como observar e Avaliar uma mamada", "Como colocar o bebê a mamar", "Como Ouvir e Perguntar" e "Como desenvolver confiança e dar apoio".
É na sequência desta decisão que nos Questionámos "Que efeito têm estes momentos de formação na prática clínica dos formandos no estágio integrado desta unidade curricular que desenvolvem nas Maternidades e Centros de Saúde?". Assim desenvolvemos um estudo com os objetivos de: conhecer os aspetos Que o enfermeiro, futuro especialista em Saúde Infantil e Pediatria, antes e depois da formação observa e avalia em uma mamada; identificar as orientações Que sugere à mãe para amamentar o seu filho/filha antes e depois da formação e verificar Que habilidades comunicacionais utiliza Quando faz aconselhamento em aleitamento materno antes e depois da formação.

\section{MÉTODOS}

O estudo realizado entre Julho e Outubro de 2008, junto dos estudantes, enfermeiros, Que frequentavam a unidade curricular vocacionada para o crescimento e desenvolvimento da criança Que faz parte do $2^{\circ}$ Semestre do Plano Curricular do Curso de Pós Licenciatura de Especialização em Enfermagem de Saúde Infantil e Pediatria de uma Escola Superior de Enfermagem, num total de 27, de tipo descritivo-comparativo, comportou um primeiro momento, Que se poderá chamar de diagnóstico das práticas dos enfermeiros, o momento de formação Que se enQuadrou nos conteúdos temáticos abordados na unidade curricular e Que seguiu as orientações dos cursos de treinamento de conselheiros em Aleitamento Materno da Organização Mundial da Saúde/Fundo das Nações Unidas para a Infância (OMS/UNICEF) $)^{(1)}$, o estágio, com uma duração de oito semanas realizado em Maternidades e Centros de Saúde, onde os formandos assistiram mães a amamentar e onde procederam à aplicação prática do protocolo de observação sistematizada da mamada preconizado pela UNICEF/OMS para identificar sinais de possíveis dificuldades na amamentação, e por último a avaliação do resultado da formação desenvolvida ou seja, da construção das aprendizagens dos formandos.

Os dados referentes ao diagnóstico das práticas dos enfermeiros e à avaliação do resultado da formação foram colhidos através de um Questionário, elaborado com Questões abertas e fechadas formuladas de acordo com os objetivos de realização do estudo, aplicado na sala de aula junto dos estudantes Que se encontravam presentes e que aceitaram participar no estudo, tendo para o efeito assinado o termo de consentimento livre e esclarecido, aplicado antes e após o início da unidade curricular. Concretamente, o Questionário Que permitiu avaliar as práticas dos formandos antes da formação foi distribuído e preenchido na sessão letiva Que antecedeu a lecionação dos conteúdos programáticos relativos à amamentação e aconselhamento em aleitamento materno e o referente à construção das suas aprendizagens foi preenchido após o términus da unidade curricular. $\mathrm{O} 1^{\circ}$ Questionário foi preenchido por 2 I estudantes (ex-ante) e o $2^{\circ}$ por 24 (ex-post), sendo que freQuentavam o curso 27.

Para a colheita de dados relativa à identificação de sinais de possíveis dificuldades na amamentação foi utilizado o protocolo de observação sistematizada da mamada preconizado pela UNICEF/ OMS.

Para a realização da pesQuisa foi feito o pedido formal de autorização para realização do estudo ao Presidente da Escola Superior de Enfermagem, Que verbalmente deu o seu consentimento. Como 
mencionado, para Que os alunos participassem no estudo foram esclarecidos Quanto aos seus objetivos e finalidades, garantida a confidencialidade das suas informações e informados das fases Que permitiriam a consecução da pesQuisa, da possibilidade de abandonarem o estudo em QualQuer momento sem QualQuer prejuízo pessoal, tendo para o efeito recebido um documento escrito onde se solicitava a sua colaboração e posteriormente assinaram o documento de aceitação de participação no estudo.

Após a aplicação dos instrumentos de recolha de informação os dados Quantitativos foram analisados utilizando-se o programa estatístico SPSS versão 15.0. Determinaram-se as frequências absolutas e percentuais e medidas da estatística descritiva tendo em atenção as caraterísticas das variáveis em estudo. Nas Questões abertas procedeu-se à análise do conteúdo das mensagens utilizando-se a categorização teórica e a contabilização das unidades de registro.

\section{RESULTADOS}

Os participantes no estudo eram majoritariamente do gênero feminino (90,5\%), tinham em média 32,7 anos, possuíam o grau académico de licenciado e trabalhavam com crianças e mães em média há 8,9 anos.

Nos dois momentos de avaliação a totalidade dos enfermeiros referiu Que Quando observavam e avaliavam uma mamada estavam atentos à posição e à pega do bebê.

Relativamente aos sinais de vínculo emocional, antes da formação constatou-se Que todos os enfermeiros observavam este aspe-cto e após a formação houve um enfermeiro que referiu não estar atento a ele.

Quanto à sucção do bebê sensivelmente a totalidade (20 do total de 21 no $1^{\circ}$ Questionário e 23 do total de 24 no $2^{\circ}$ Questionário) mencionou ser um aspeto Que observavam Quando avaliavam uma mamada.

Observando a Tabela 1 constata-se Que do $1^{\circ}$ para o $2^{\circ}$ Questionário foi maior a percentagem de enfermeiros Que passaram a estar despertos para a postura corporal materna e para a anatomia da mama.

Quanto aos sinais Que permitem identificar uma pega correta Quando a criança está a mamar, apurou-se Que no $2^{\circ}$ momento de ava-liação os resultados tiveram um incremento para todos os itens à exceção de "língua da criança acoplada à mama da mãe" e "ouvir-se a criança a deglutir".

No primeiro momento de avaliação Questionou-se os participantes se conheciam o protocolo para observação da mamada preconizado pela UNICEF/OMS, obtendo-se resposta afirmativa de apenas Quatro participantes no entanto, nenhum dos 24

Tabela 1. Distribuição do número de enfermeiros atentos à Postura Corporal Materna $\mathrm{e}$ à Anatomia da Mama Quando observam e avaliam uma mamada.

\begin{tabular}{lcccc}
\hline \multirow{2}{*}{ Postura Corporal Materna } & \multicolumn{2}{c}{$\mathbf{1}^{\circ}$ Questionário } & \multicolumn{2}{c}{$2^{\circ}$ Questionário } \\
\cline { 2 - 5 } & $\mathbf{n}$ & \% & n & \% \\
\hline Sim & 18 & 85,8 & 23 & 95,8 \\
Não & 3 & 14,2 & 1 & 4,2 \\
Anatomia da Mama & & & & \\
Sim & 14 & 66,7 & 23 & 95,8 \\
Não & 7 & 33,3 & 1 & 4,2 \\
\hline
\end{tabular}

Tabela 2. Distribuição do número de enfermeiros relativamente aos Conselhos dados às mães para amamentar o bebê.

\begin{tabular}{|c|c|c|c|c|}
\hline \multirow{2}{*}{ Conselhos Quanto ao posicionamento do bebé } & \multicolumn{2}{|c|}{$1^{\circ}$ Questionário } & \multicolumn{2}{|c|}{$2^{\circ}$ Questionário } \\
\hline & $\mathrm{n}$ & $\%$ & $n$ & $\%$ \\
\hline \multicolumn{5}{|l|}{$\begin{array}{l}\text { Corpo do bebê alinhado (orelha, ombro e anca em } \\
\text { linha reta) }\end{array}$} \\
\hline Sim & 11 & 52,3 & 21 & 87,5 \\
\hline Não & 9 & 42,9 & 3 & 12,5 \\
\hline Não Responderam & 1 & 4,8 & - & - \\
\hline \multicolumn{5}{|l|}{$\begin{array}{l}\text { O rosto do bebê deve estar de frente para a mama, } \\
\text { com o nariz em linha reta de frente para o mamilo }\end{array}$} \\
\hline Sim & 6 & 28,5 & 23 & 95,8 \\
\hline Não & 14 & 66,7 & 1 & 4,2 \\
\hline Não Responderam & 1 & 4,8 & - & - \\
\hline \multicolumn{5}{|l|}{$\begin{array}{l}\text { O rosto do bebê deve estar de frente para a mama, } \\
\text { com a boca de frente para o mamilo }\end{array}$} \\
\hline Sim & 16 & 76,2 & 2 & 8,3 \\
\hline Não & 4 & 19,0 & 22 & 91,7 \\
\hline Não Responderam & 1 & 4,8 & - & - \\
\hline \multicolumn{5}{|l|}{ A mãe deve segurar o bebê junto a ela } \\
\hline Sim & 17 & 81,0 & 17 & 70,8 \\
\hline Não & 3 & 14,2 & 7 & 29,2 \\
\hline Não Responderam & 1 & 4,8 & - & - \\
\hline
\end{tabular}


Tabela 3. Distribuição do número de enfermeiros relativamente aos Conselhos dados às mães sobre a freQuência, duração e técnica das mamadas.

\begin{tabular}{|c|c|c|c|c|}
\hline \multirow{2}{*}{ FreQuência da Mamada } & \multicolumn{2}{|c|}{$1^{\circ}$ Questionário } & \multicolumn{2}{|c|}{$2^{\circ}$ Questionário } \\
\hline & $\mathrm{n}$ & $\%$ & $\mathrm{n}$ & $\%$ \\
\hline Sempre Que Quer & 14 & 66,7 & 23 & 95,8 \\
\hline Com intervalos regulares & 7 & 33,3 & 1 & 4,2 \\
\hline \multicolumn{5}{|l|}{ Duração } \\
\hline Durante o tempo Que Quer & 16 & 76,3 & 23 & 95,8 \\
\hline Durante um tempo determinado & 5 & 23,7 & 1 & 4,2 \\
\hline \multicolumn{5}{|l|}{ Técnica } \\
\hline $\begin{array}{l}\text { De uma ou das duas mamas, segundo a } \\
\text { vontade do bebé }\end{array}$ & 16 & 76,3 & 19 & 79,2 \\
\hline Só de uma mama & 3 & 14,2 & 5 & 20,8 \\
\hline $\begin{array}{l}\text { Sempre das duas mamas em cada } \\
\text { mamada, interrompendo a mamada para } \\
\text { Que o bebê mame sempre das duas } \\
\text { mamas }\end{array}$ & 2 & 9,5 & - & - \\
\hline
\end{tabular}

Tabela 4. Distribuição do número de enfermeiros relativamente aos aspetos a Que estão atentos Quando fazem aconselhamento em aleitamento materno.

\begin{tabular}{|c|c|c|c|c|}
\hline \multirow{2}{*}{ Aspectos da Comunicação } & \multicolumn{2}{|c|}{$1^{\circ}$ Questionário } & \multicolumn{2}{|c|}{$2^{\circ}$ Questionário } \\
\hline & $\mathrm{n}$ & $\%$ & $\mathrm{n}$ & $\%$ \\
\hline \multicolumn{5}{|l|}{ Aspetos da Comunicação Ouvir e } \\
\hline \multicolumn{5}{|l|}{ Perguntar } \\
\hline Usar comunicação não verbal útil & 10 & 47,6 & 12 & 50,0 \\
\hline Fazer perguntas abertas & - & - & - & - \\
\hline $\begin{array}{l}\text { Usar expressões e gestos que } \\
\text { demonstrem interesse }\end{array}$ & 3 & 14,2 & 6 & 25,0 \\
\hline $\begin{array}{l}\text { Devolver o Que a mãe diz com palavras } \\
\text { suas }\end{array}$ & - & - & - & - \\
\hline $\begin{array}{l}\text { Empatia - demonstrar à mãe Que } \\
\text { compreende o Que ela sente }\end{array}$ & - & - & 5 & 20,8 \\
\hline Evitar palavras Que soam a julgamento & - & - & 2 & 8,3 \\
\hline \multicolumn{5}{|l|}{ Aspetos da Comunicação Desenvolver } \\
\hline \multicolumn{5}{|l|}{ Confiança e Dar Apoio } \\
\hline Aceitar o que a mãe pensa ou sente & 1 & 4,8 & - & - \\
\hline $\begin{array}{l}\text { Reconhecer e elogiar o Que a mãe e o } \\
\text { bebê estão a fazer certo }\end{array}$ & - & - & 2 & 8,3 \\
\hline Dar ajuda prática & - & - & 3 & 12,5 \\
\hline Dar informação de relevância imediata & 1 & 4,8 & 5 & 20,8 \\
\hline Adequar a linguagem & 8 & 38,1 & 4 & 16,7 \\
\hline Sugerir sem dar ordens & 2 & 9,5 & 4 & 16,7 \\
\hline
\end{tabular}

respondentes do segundo momento referiu ter tido dificuldades durante a sua utilização.

Quanto aos conselhos dados às mães sobre como dar de mamar ao filho, apurámos Que antes da formação "Levar o bebê à mama" foi uma indicação dada por apenas 14 enfermeiros e Que após as aulas esta informação foi difundida por 18 participantes.

Relativamente aos conselhos dados às mães para colocarem o bebê à mama observa-se na Tabela 2 Que após a formação houve mais enfermeiros a informarem sobre "Corpo do bebê alinhado" e "Rosto do bebê deve estar de frente para a mama, com o nariz em linha reta, de frente para o mamilo" (Tabela2).

Relativamente à forma de agarrar a mama, se necessário, observou-se Que no primeiro momento só 12 enfermeiros aconselharam agarrar a mama "com o polegar por cima da aréola e os outros dedos por baixo, formando um C", comparativamente aos 22 do $2^{\circ}$ Questionário.

Como se pode observar na Tabela 3 relativamente aos conselhos dados às mães sobre a frequência, duração e técnica das mamadas, após a lecionação dos conteúdos, houve mais enfermeiros a informarem "Amamentar sempre Que Quer", "Durante o tempo que Quer" e "De uma ou das duas mamas, segundo a vontade do bebê".

A maioria dos aspetos Que o enfermeiro necessita desenvolver e indicados pela OMS para Ouvir e Perguntar e Desenvolver Confiança e dar apoio, de modo a ajudar a mãe a amamentar e a tomar a decisão do que fazer, foram abordados por um número pequeno de enfermeiros e sobretudo após a formação, como se pode observar na Tabela 4. 


\section{DISCUSSÃO}

Considerando-se que rotinas hospitalares e práticas de profissionais de saúde podem facilitar o estabelecimento e a duração do aleitamento materno, a OMS/UNICEF centram esforços para a instituição de uma política pública de incentivo à amamentação Que enfatiza a avaliação da mamada por meio do formulário de observação e avaliação sistematizada onde se destaca a importância de observar dois pontos-chave, o posicionamento e a pega ${ }^{(6)}$. Tivemos oportunidade de observar no nosso estudo que os estudantes Que frequentavam o Curso de Pós Licenciatura de Enfermagem de Saúde Infantil e Pediatria em ambos os momentos de avaliação estavam todos eles atentos a estes dois aspectos. Tendo em conta Que a posição ina-dequada da mãe e/ou do bebê dificulta o posicionamento correto da boca do bebê na mama originando uma má pega, este resultado poderá ser revelador Que estamos presente a profissionais de enfermagem informados sobre como estes dois aspetos são importantes e influenciam a dinâmica de sucção e extração de leite e como podem interferir na anatomia ma-mária e na ocorrência de dor e desconforto na mãe, podendo mesmo condicionar a continuidade da amamentação(6).

A amamentação é um momento privilegiado de comunhão, em Que a mãe e o filho podem ler-se, um ao outro, olhos nos olhos e sentir-se mais fundo um no outro ${ }^{(7)}$ pelo Que também é importante observar, Quando se observa e avalia uma mamada, o vínculo entre a mãe e o filho através da forma de se-gurar o bebê, pelo toque e contato visual ${ }^{(6)}$. Os nossos achados são concordantes com os autores pois Que, os enfermeiros do estudo, revelaram estar atentos ao vínculo emocional revelando Que são conhecedores Que a amamentação não é só dar o líquido, mas sim estabelecer uma relação( ${ }^{(2)}$.

Quanto à sucção do bebé, $1^{\circ}$ modo Que tem para entrar em contato com o mundo externo, resposta congénita, inata, internamente organizada, altamente complexa e variável entrando em linha de conta com a natureza do estímulo com Que contata ${ }^{(2)}$, funcional desde o nascimento e componente importante do ato complexo da alimentação, Que deve ser entendida como um conjunto de duas ações, em Que primeiramente o RN faz a tração do tecido mamário para formar um bico e posteriormente exerce pressão na aréola tracionada contra o palato com a língua ${ }^{(8)}$ verificamos, nos dois momentos de avaliação, ser um aspeto Que sensivelmente a totali-dade dos inquiridos observavam Quando avaliavam uma mamada. Estes resultados poderão indicar que ao observar e avaliar as díades durante a mamada, relativamente a este aspeto, os estudantes estavam atentos a verificar se os movimentos de retirada de leite, exercidos pelas mandíbulas, eram suaves, coordenados com o ritmo de deglutição e respiração, se a criança não apresentava bochechas côncavas e se as sucções eram lentas e profundas, com pausas ${ }^{(6)}$.

Uma posição inadequada da mãe dificulta o posicionamento correto do bebê à mama, o Que pode resultar numa má pega e conseQuentemente situações de ingurgitamento e traumas mamilares pelo Que, para Que seja possível mamar em boa posição, é também importante Que a mãe esteja sentada ou deitada num lugar confortável, por forma a Que fieue relaxada, e Que os enfermeiros estejam atentos para as condições gerais das mamas e mamilos ${ }^{(2,6,9)}$. Foi neste sentido Que também no nosso estudo verificámos Que o fato dos estudantes terem tido oportunidade de frequentarem as sessões letivas passaram a estar mais despertos para estes dois aspetos.
Esta constatação reforça a ideia Que é imprescindível investir mais na formação e no aperfeiçoamento dos profissionais de saúde sobre a prática do aleitamento materno.

São sinais indicativos de uma pega correta o Queixo encostado à mama, o lábio inferior voltado para fora, boca bem aberta, mais aréola visível acima do Que por baixo da boca do bebê, bochechas arredondadas, língua acoplada à mama, sucção lenta e profunda e poder ouvir-se o bebê a deglutir ${ }^{(1-2,6,10-14)}$. No nosso estudo verificamos Que com a formação passou a estar maior número de estudantes atento à maioria dos sinais indicativos de uma pega correta mas não foi suficiente para os despertar para a necessidade de ficarem atentos para o posicionamento da língua e de Que por vezes também se pode ouvir a criança a deglutir. Estes achados deixam-nos preocupados sobretudo no Que se refere ao posicionamento da língua tendo presente a sua importância na extração de leite. Sabe-se que a sucção ajuda a puxar e manter o tecido mamário na boca da criança, no entanto, a sucção só por si não retira o leite. Para sugar eficientemente e conseguir leite, a criança precisa de pegar uma Quantidade suficiente da mama na boca de tal forma Que possa exercer pressão com a língua ${ }^{(2)}$

Embora estivéssemos a trabalhar com estudantes já profissionais de enfermagem, Que como apurámos em média trabalhavam com mães e crianças em média de 8-9 anos, e seja uma das medidas recomendadas pela OMS/UNICEF avaliar e observar as mães a amamentar e treinar toda a equipa de saúde para ajudarem as mães a amamentarem, constatámos Que só Quatro estudantes conheciam o protocolo de observação da mamada. Frequentar as sessões letivas e ter tido oportunidade de utilizar o formulário durante o estágio constituiu uma apropriação de novos saberes para estes formandos que se traduziu numa experiência sem dificuldades na sua utilização.

Temos de dar tempo ao bebê para explorar a mama antes de mamar, até Que este se decida a abrir bem a boca e colocar a língua na posição adeQuada e então sim aproximá-lo da mama segurando-o pelas costas e não pela cabeça. Em vez disto, muitas vezes, o Que acontece, é observarmos mães a inclinarem-se sobre os seus bebês e permanecerem inclinadas durante toda a mamada. Esta posição não será de todo confortável para a mãe, provocar-lhe-á no futuro lombalgias e alguns bebês têm dificuldades em suster a cabeça para mamar ${ }^{(12)}$. Foi tendo em conta este aspeto Que Quisemos saber como os estudantes aconselhavam as mães a amamentar antes e depois da formação. Apurámos Que, embora após a formação, tivesse aumentado o número de enfermeiros a aconseIhar as mães a levarem as crianças à mama, na nossa perspectiva este valor é ainda reduzido, dado as consequências para a saúde da mãe e porQue a criança necessita de fazer uma ligeira extensão da cabeça para oue possa facilmente deglutir, respirar e retirar o leite eficazmente.

Vários autores $^{(1-2,6,10-14)}$ são unânimes a afirmar Que a criança corretamente colocada à mama deverá estar junto à mãe, com a cabeça e os ombros frente à sua mama, encontrando-se todo o corpo do bebê alinhado em contato com a mãe, e o seu nariz ao mesmo nível Que o mamilo. Tendo em conta a importância da colocação do bebê à mama na prevenção de problemas na amamentação, os resultados a Que chegámos revelam-nos Que, após a formação, os estudantes melhoraram os seus conhecimentos sobre a colocação do bebê à mama e conseQuentemente passaram a acon- 
selhar as mães a melhor colocar o bebê a mamar.

Pode-se afirmar Que agarrar a mama "Com os dedos indicador e médio próximo do mamilo, formando uma tesoura” em Portugal é cultural. Todavia, se a mãe mantiver os dedos junto ao mamilo provavelmente impede o bebê de o agarrar eficazmente. Recomenda-se Que a mãe não aperte a mama de forma alguma ou, em caso de necessidade, Que o faça com o polegar por cima da aréola e os outros dedos por baixo, formando um amplo $\mathrm{C}^{(2,12,15)}$. Verificamos Que, após a formação, houve incremento no número de enfermeiros Que passaram a aconselhar as mães a suster as suas mamas desta forma. Este resultado pode indicar Que os estudantes perceberam a importância Que ao mamar a criança pegue uma Quantidade suficiente de aréola e tecido mamário, em Que o mamilo apenas representa cerca de $1 / 3$ do Que tem dentro da boca, e a sua influência na produção do leite.

Quisemos também saber como aconselhavam as mães a amamentar as suas crianças, destacando-se Que, após a formação, os estudantes informavam sobre o horário livre das mamadas, outra medida de incremento da amamentação, Que tem diversas vantagens fisiológicas e psicológicas. As refeições administradas a pedido da criança vão responder melhor às suas necessidades, ela própria regula a intensidade da sucção e a duração da mamada para ter o aporte de leite Que a sacie e lhe traga o bem estar ${ }^{(2)}$.

Os profissionais de saúde Que lidam com mães Que estão a amamentar têm de estar conscientes Que para o êxito e sucesso da amamentação as mães têm de receber apoio e ajuda centrada nas dificuldades específicas ou nas suas crises de autoconfiança ${ }^{(5)}$ pelo Que, é essencial Que desenvolvam um conjunto de competências comunicacionais. Foi neste sentido Que Quisemos saber Que habilidades comunicacionais os estudantes desenvolviam junto das mães nas suas práticas clínicas. Apurámos Que a formação produziu mudanças, reconhecendo-se Que houve mais habilidades comunicacionais a serem utilizadas todavia, revelou-se ser reduzido o número de estudantes Que as utilizaram. Este fato poderá estar associado a ser esta uma temática pouco abordada e por isso constituir novidade para os nossos formandos.

\section{CONCLUSÃO}

Os enfermeiros antes da lecionação dos conteúdos já estavam despertos para a maioria dos aspetos Quando se observa e avalia uma mamada tendo-se observado Que houve incremento dos valores nos itens postura corporal materna e anatomia da mama.

Tendo em conta a importância da pega correta da mama para Que a criança mame de forma eficaz e assim consiga sugar e retirar leite de forma eficiente, constatou-se Que, embora tenha havido aumento no número de enfermeiros a referirem estarem atentos aos aspetos a considerar numa pega correta, os valores obtidos revelaram-se insuficientes.

O fato da utilização do protocolo para observação da mamada preconizado pelo UNICEF/OMS se ter revelado de fácil utilização poderá constituir motivo para Que os enfermeiros o adotem nas suas práticas sempre Que observem e avaliem uma mamada.

Verificou-se Que após a lecionação dos conteúdos houve modificação dos conselhos dados às mães para práticas mais adeQuadas sobre como colocar o bebê à mama e deixar o bebê mamar de acordo com as suas necessidades.

A formação dos profissionais de enfermagem sobre aconselhamento em aleitamento materno não foi suficiente. ReQuer mais horas de desenvolvimento. Fazer aconselhamento em aleitamento materno exige Que antes de se discutir com a mãe como ela amamenta, Que se pense nela como pessoa, nas suas dificuldades e problemas. O sucesso da amamentação depende mais do bem-estar da mulher, de como ela se sente a respeito de si própria e da sua situação de vida. O desenvolvimento destas habilidades comunicacionais, nem sempre fácil, implica mudança de atitudes e de perspectiva, implica aprender a captar, respeitar e responder ao outro a partir do seu ponto de vista e não apenas do profissional de saúde.

\section{REFERÊNCIAS}

1. Organização Mundial de Saúde. UNICEF. Aconselhamento em amamentação: Um curso de treinamento. Manual do participante. São Paulo: Ed. Nelson Francisco Brandão, 1995.

2. Galvão DMPG. Amamentação bem sucedida: alguns factores determinantes. Loures: Lusociência; 2006.

3. Carvalhaes MABL, Corrêa CRH. Identificação de dificuldades no início do aleitamento materno mediante aplicação de protocolo. I Pediatr 2003; 79(1).

4. Martins RMC, Montrone AVG. Implementação da iniciativa Unidade Básica Amiga da Amamentação: educação continuada e prática profissional. Rev Eletrônica Enferm [serial online] 2009; I I (3):545-553. Disponível em: http://www.fen.ufg.br/ revista/vI I/n3/vI In3al I.htm.

5. Bueno LGS, Teruya KM. Aconselhamento em amamentação e sua prática. I Pediatr 2004;80(5 Supl): SI26-30.

6. Sanches MTC. Manejo clínico das disfunções orais na amamentação. J Pediatr 2004; 80(5 Supl): S155-62.

7. Sá E. Prefácio. In: Galvão DMPG, organizadores. Amamentação bem sucedida: alguns factores determinantes. Loures: Lusociência; 2006.

8. King FS. Como ajudar as mães a amamentar. Londrina: Universidade Estadual de Londrina; 1991.

9. Pereira MA, Levy L, Matos ME, Calheiros JM. Influência da correcção da pega no sucesso do Aleitamento Materno: resultados de um estudo experimental. Rev Referência 2008; 2(6): 27-38

10. Royal College of Midwives. Lactancia materna Manual para profissionales. Barcelona: Assocación Catalana Pro Alletament Matern; 1994.

11. Oraganização Munidal de Saúde. Alimentação infantil. Bases fisiológicas. São Paulo: OMS; 1994.

12. Gonzales C. Manual prático de lactancia materna. Barcelona: ACPAM; 2004

13. Giugliani ERJ. Amamentação exclusiva e sua promoção. In: Carvalho M, Taméz R, organizadores. Amamentação: bases científicas para a prática profissional. Rio de Janeiro: Guanabara Koogan; 2005.

14. Levy L, Bértolo H. Manual do Aleitamento Materno. Lisboa: Comité Português para a UNICEF/ Comissão Nacional Iniciativa Hospitais Amigos dos Bebés; 2008. 
Galvão DG.

15. Pereira MA. Aleitamento materno: importância da correcção da pega no sucesso da amamentação - resultado de um estudo experimental. Loures: Lusociência; 2006. 